\title{
A Meta-Analysis of the Price Elasticity of Meat: Evidence of Regional Differences
}

\author{
Craig A. Gallet \\ Dept. of Economics, California State University, Sacramento \\ 6000 J Street, Sacramento, CA, United States \\ Tel: 916-278-6099Ｅ-mail: cgallet@ csus.edu
}

Received: July 17, 2012 Accepted: July 30, 2012

doi:10.5296/ber.v2i2.2115 URL: http://dx.doi.org/10.5296/ber.v2i2.2115

\begin{abstract}
This study addresses regional differences in meat demand by estimating meta-regressions of the price elasticity of meat for North America, Europe, and Asia. Although we find many characteristics in the literature have similar impacts on the price elasticity across these regions, there are noticeable differences. For instance, the price elasticities of beef, lamb, and fish in North America are significantly more elastic compared to poultry. For Asia and Europe, though, there are fewer significant differences in the price elasticity across meats. Also, demand specification plays a more prominent role in determining the price elasticity of meat in Europe.
\end{abstract}

Keywords: Meat demand, Price elasticity, Meta-analysis, Regional differences

\section{Introduction}

Many studies estimate the price elasticity of meat utilizing various data and estimation methods, which several qualitative literature reviews, such as Kuznets (1953), Tomek (1977), Smallwood et al. (1989), and Asche et al. (2007), suggest contribute to differences in reported elasticity estimates. Yet qualitative literature reviews can be sensitive to the subjective decision of the reviewer to emphasize particular study characteristics over others, and so meta-analysis has been increasingly used as a tool to quantitatively survey literature. In a typical meta-analysis, a parameter commonly estimated in the literature, such as the price elasticity, is regressed on a series of dummy variables controlling for study characteristics. By utilizing regression techniques, the subjective decision of the reviewer is thus replaced by statistical tests, the results of which shed light on the statistical influence of study characteristics on the parameter estimate. Examples of such analyses include Espey (1998), 
Dalhuisen et al. (2003), Gallet and List (2003), Johnston et al. (2006), Gallet (2007), and Gallet (2010).

Concerning the demand for meat, Gallet (2010) reports results of a meta-analysis of the price elasticity. In his study, 4120 estimates of the price elasticity of meat, collected from 419 studies, were regressed on variables that control for the type of meat, demand specification, nature of the data used to estimate demand, estimation method, publication outlet, and demand location. He finds beef, lamb, and fish demand are more responsive to price, while poultry demand is less responsive to price. Also, although the price elasticity of meat is particularly sensitive to a number of specification, estimation, and publication characteristics, data issues and the location of demand have less influence on the price elasticity.

A typical meta-analysis constructs a meta-data set by compiling information from studies across multiple regions. For example, Gallet's (2010) meta-data includes studies of meat demand in North America, Asia, and Europe, as well as a few other regions. Although meta-analyses often control for regional differences by including region dummy variables in the meta- regressions, this holds the marginal effects constant across regions. With respect to Gallet (2010), while he finds some regional differences in the price elasticity of meat, the rank order of the price elasticity across study characteristics is held constant in each region. ${ }^{1}$ Yet there may not only be regional differences in the price elasticity of meat, but also regional differences in the impact of each study characteristic on the price elasticity, and so this study extends Gallet (2010) by reporting the results from estimating separate meta-regressions of the price elasticity for North America, Europe, and Asia, the three regions most commonly studied in the literature. ${ }^{2}$

Although there are a number of similarities in the meta-regression results across the three regions, we do find regional differences in the pattern of the price elasticity of meat. For example, the price elasticities of beef, lamb, and fish in North America are significantly higher in absolute value compared to poultry, but significant differences in the price elasticity across meat products drop off for Asia and Europe. Furthermore, demand specification plays a more prominent role in determining the price elasticity of meat in Europe, compared to North America and Asia.

In the sections that follow, Section 2 presents the data and meta-regression model. This is followed in Section 3 with a discussion of the estimation results. A conclusion is provided in Section 4.

${ }^{1}$ For example, beef, lamb, and fish are more price elastic than poultry, irrespective of region.

2 Most meta-analyses of the economics literature compile meta-data from a relatively small number of studies (often less than 100), such that the sacrifice in degrees of freedom to estimate region-specific meta-regressions is substantial. Because Gallet's (2010) meta-data set is relatively large, though, we can address regional differences in meat demand and still maintain a high degree of freedom in each region's meta-regression. 


\section{Data and Meta-Regression Model}

\subsection{Data}

To compile the data, a search using EconLit, AgEcon Search, and Google Scholar, as well as a perusal of Kuznets (1953), Reeves and Hayman (1975), Tomek (1977), Raunikar and Huang (1987), Smallwood et al. (1989), Alston and Chalfant (1991), Moschini and Moro (1996), and Asche et al. (2007), led to an initial set of candidate studies. Subsequent to surveying the reference sections of these studies, 362 studies were identified as estimating the price elasticity of meat in North America, Asia, or Europe. ${ }^{3}$ These 362 studies provided 3755 estimates of the price elasticity, with the largest number (1672) corresponding to North America, followed by Europe (1063) and Asia (1020). ${ }^{4}$

Similar to meta-analyses of Espey (1998), Dalhuisen et al. (2003), Gallet and List (2003), Gallet (2007), and Gallet (2010), we collected information on several characteristics of the 362 studies. First, the price elasticity has been estimated for a number of meats, including beef, pork, lamb, poultry, fish, and a composite of multiple meats. ${ }^{5}$ Second, with respect to demand specification, although many studies estimate linear or double-log functional forms, many others estimate functional forms that are consistent with consumer theory, such as the linear-approximate almost ideal demand system (AIDS-Linear), which uses a price index to linearize Deaton and Muellbauer's (1980) AIDS form. Other less common forms that have been estimated include the following: the traditional nonlinear AIDS form (AIDS-Nonlinear), the quadratic AIDS form (AIDS-Quadratic) of Banks et al. (1997), the generalized AIDS form (AIDS-General) of Bollino (1990), the Rotterdam form, the CBS form, the translog form, the S-Branch form, the Box-Cox form, the generalized addilog form, and the quadratic expenditure form.

Third, in addition to functional form, a number of other specification issues have been addressed in the literature. Several studies estimate compensated price elasticities, which provided meat is a normal good are expected to be lower in absolute value compared to uncompensated price elasticities. A number of studies include other meats as substitutes in the specification of demand, or estimate a dynamic specification of demand (i.e., include lag terms in the demand equation), or estimate a two-step specification (i.e., the demand for meat

${ }^{3}$ Complete references of the 362 studies are available upon request.

4 Although not impacting the sign and significance of the meta-regression coefficients, similar to Gallet (2010) unusually large observations of the price elasticity (i.e., those more than three standard deviations from the mean) were thrown out of the meta-data to reduce the impact of outliers. We also followed a procedure outlined by Bellavance et al. (2009) to identify outliers. Specifically, we split the price elasticities into quartiles and then constructed the following: (observed value - median)/(interquartile range). Bellavance et al. (2009) deem as outliers any observation for which this construction exceeds three in absolute value. This also led to the removal of these unusually large price elasticities.

5 The composite consists of studies that aggregate a number of different meats into a single category. 
is modeled as (i) the choice of whether or not to consume meat followed by (ii) the choice of how much meat to consume).

Fourth, we note several data and estimation characteristics of the 362 studies. Studies not only differ in terms of whether time-series, cross-sectional, or panel data is used, but also differ in terms of the level of data aggregation, be it at the multiple country, country, region of country, city, firm, or individual consumer levels. We also collected information on the median year of the sample used to estimate meat demand, which if found to impact the price elasticity estimate could signal changes in consumer preferences over time. Various methods have been used to estimate the demand for meat, including ordinary least squares (OLS), two stage least squares (2SLS), three stage least squares (3SLS), full information maximum likelihood (FIML), single-equation maximum likelihood (MLE), seemingly unrelated regression (SUR), generalized method of moments (GMM), generalized least squares (GLS), and sparingly the minimum distance and maximum entropy estimators.

Common to many meta-analyses, we also collected information on several characteristics of the publication outlet. Specifically, we note whether or not the study was published in a premier journal, such as a top 36 economics journal (identified by Scott and Mitias (1996) or the top-ranked American Journal of Agricultural Economics (AJAE), as well as whether or not the study was published as a chapter in a book. See Gallet (2010) for the frequencies of these study characteristics in the literature.

\subsection{Meta-Regression Model}

The estimated price elasticity of meat is used as the dependent variable in a series of meta-regressions, with study characteristics serving as determinants of the price elasticity. Specifically, since it is common for studies to report multiple price elasticity estimates, we follow Rosenberger and Loomis (2000), Gallet and List (2003), Johnston et al. (2006), and Gallet (2010) by considering an unbalanced panel meta-regression model, given by:

$$
\mathrm{P}_{\mathrm{ij}}=\alpha_{\mathrm{i}}+\beta \mathrm{X}_{\mathrm{ij}}+\varepsilon_{\mathrm{ij}}
$$

where $P_{i j}$ is the $j$ th price elasticity estimate from study $i, \alpha_{i}$ is a "random researcher" effect, $\beta$ is a vector of coefficients, and $X_{i j}$ accounts for study characteristics. In $X_{i j}$, we include the median year of the sample used to estimate the respective price elasticity, as well as a series of dummy variables accounting for the study characteristics mentioned in the previous subsection (i.e., variable equals 1 if the respective study characteristic holds, 0 if not). ${ }^{6}$ Finally, $\varepsilon_{\mathrm{ij}}$ is an iid error term with zero mean and variance $\sigma_{\varepsilon}^{2}$.

There are a number of issues concerning the estimation of equation (1). First, OLS and random effects versions of equation (1) are estimated separately for North America, Asia, and Europe. $^{7}$ This allows us to not only see how sensitive the results are to addressing panel data

${ }^{6}$ Similar to Gallet (2010), the generalized addilog and quadratic expenditure forms are controlled for by a variable labeled "Other Form", while the minimum distance and maximum entropy estimators are controlled for by a variable labeled "Other Method".

${ }^{7}$ Some characteristics do not vary within studies, which prevents the use of fixed effects. 
issues, but to also draw comparisons in the nature of the price elasticity across the three regions. Second, since some study characteristics do not apply in all three regions, the dummy variables corresponding to those characteristics must be dropped from the meta-regressions in which they do not apply. ${ }^{8}$ Some sets of study characteristics (e.g., type of meat, functional form of demand, nature of data, and estimation method) encompass all observations, and so to avoid perfect multicollinearity we must drop several dummy variables from each meta-regression. Along with these dummy variables, setting all included dummy variables equal to zero defines the baseline to which the estimation results are compared. ${ }^{9}$ Third, we use White's (1980) procedure to adjust standard errors for heteroskedasticity. Fourth, since the price elasticity is typically negative, a negative (positive) coefficient of a particular study characteristic implies that characteristic makes the price elasticity more (less) elastic.

\section{Estimation Results}

\subsection{Meta-Regression Results}

The OLS and random effects results for each region are provided in Table 1. As indicated at the bottom of the table, the LaGrange Multiplier test favors using random effects over OLS in each region. Rather than discuss the results of each estimation separately, we will compare the general pattern of the coefficients across the three regions.

\footnotetext{
8 There are no observations of the S-Branch and Box-Cox forms for Asia, nor are there observations of the generalized AIDS and S-branch forms for Europe. Concerning aggregation, the meta-data does not contain multiple country observations for North America, multiple country and firm-level observations for Asia, and city-level and firm-level observations for Europe. Application of the minimum distance and maximum entropy estimators are only observed for North America, while GMM estimation is not observed for Europe.

9 We drop from the meta-regressions the dummy variables corresponding to the meat composite, the linear functional form, panel data, data at the individual consumer level, and OLS estimation of meat demand. In addition to these dropped characteristics, the baseline thus corresponds to the uncompensated price elasticity of meat (absent substitute meats, two-step estimation, and dynamic considerations) which is not published in a top 36 economics journal, AJAE, or a book.
} 
Table 1. Meta-regression results

\begin{tabular}{|c|c|c|c|c|c|c|}
\hline & & $\underline{\text { OLS }}$ & & & Random Effects & \\
\hline Variable & North America & Asia & Europe & North America & Asia & Europe \\
\hline \multicolumn{7}{|l|}{ Product: } \\
\hline \multirow[t]{2}{*}{ Beef } & $-0.120^{*}$ & -0.133 & $-0.150^{*}$ & $-0.154^{* * *}$ & $-0.264^{* * *}$ & -0.106 \\
\hline & (1.898) & (1.597) & (1.793) & $(3.012)$ & $(3.021)$ & (1.359) \\
\hline \multirow[t]{2}{*}{ Pork } & 0.052 & 0.040 & $-0.104^{*}$ & -0.018 & -0.069 & -0.049 \\
\hline & $(1.333)$ & $(0.488)$ & $(1.873)$ & $(0.464)$ & $(0.748)$ & $(0.801)$ \\
\hline \multirow[t]{2}{*}{ Lamb } & $-0.316^{* *}$ & -0.143 & -0.116 & $-0.390^{* * *}$ & $-0.285^{* *}$ & 0.006 \\
\hline & (2.038) & (1.336) & $(0.980)$ & $(2.224)$ & $(2.385)$ & $(0.053)$ \\
\hline \multirow[t]{2}{*}{ Poultry } & $0.221^{* * * *}$ & 0.004 & -0.020 & $0.156^{* * * *}$ & -0.107 & 0.040 \\
\hline & $(5.487)$ & $(0.050)$ & $(0.278)$ & $(4.248)$ & (1.239) & $(0.600)$ \\
\hline \multirow[t]{2}{*}{ Fish } & $-0.286^{* * *}$ & -0.054 & $0.076^{*}$ & $-0.212^{* * *}$ & -0.093 & $0.108^{* * * *}$ \\
\hline & $(3.777)$ & $(0.604)$ & (1.691) & $(3.996)$ & $(0.909)$ & $(2.862)$ \\
\hline \multicolumn{7}{|l|}{ Functional Form: } \\
\hline \multirow[t]{2}{*}{ Double-Log } & $-0.167^{*}$ & -0.216 & $-0.513^{* * *}$ & -0.092 & -0.180 & -0.511 \\
\hline & $(1.877)$ & $(1.310)$ & $(2.600)$ & $(0.888)$ & $(0.862)$ & $(1.401)$ \\
\hline \multirow[t]{2}{*}{ Semi-Log } & $0.456^{* *}$ & $-0.229^{* *}$ & $-2.057^{* * * *}$ & 0.152 & -0.155 & $-1.029^{* *}$ \\
\hline & (2.299) & $(2.089)$ & $(5.825)$ & $(0.669)$ & (1.108) & (2.387) \\
\hline \multirow[t]{2}{*}{ AIDS-Nonlinear } & $0.220^{* *}$ & -0.072 & $-0.550^{* * *}$ & 0.128 & -0.087 & $-0.537^{* * *}$ \\
\hline & $(2.356)$ & $(0.566)$ & $(5.369)$ & (1.028) & $(0.525)$ & $(2.904)$ \\
\hline \multirow[t]{2}{*}{ AIDS-Linear } & 0.028 & $-0.241^{* *}$ & $-0.530^{* * *}$ & 0.015 & -0.167 & $-0.388^{* *}$ \\
\hline & $(0.361)$ & $(2.150)$ & $(5.484)$ & $(0.151)$ & (1.101) & (1.991) \\
\hline \multirow[t]{2}{*}{ AIDS-Quadratic } & -0.120 & $-0.290^{* *}$ & $-0.607^{* *}$ & -0.207 & $-0.343^{*}$ & -0.458 \\
\hline & $(0.573)$ & (2.509) & $(2.400)$ & $(0.710)$ & (1.918) & (1.102) \\
\hline \multirow[t]{2}{*}{ AIDS-General } & -0.003 & $0.281^{* *}$ & --- & -0.021 & 0.208 & --- \\
\hline & $(0.035)$ & (2.484) & & $(0.161)$ & (1.293) & \\
\hline \multirow[t]{2}{*}{ Rotterdam } & -0.143 & -0.153 & $-0.781^{* * *}$ & -0.038 & -0.108 & $-0.631^{* * *}$ \\
\hline & (1.337) & (1.215) & $(4.083)$ & $(0.322)$ & $(0.361)$ & (2.918) \\
\hline \multirow[t]{2}{*}{ CBS } & $0.649^{* *}$ & 0.026 & $-0.577^{* * *}$ & 0.403 & 0.119 & $-0.454^{*}$ \\
\hline & $(2.573)$ & $(0.168)$ & $(4.791)$ & (1.328) & $(0.439)$ & (1.940) \\
\hline \multirow[t]{2}{*}{ Translog } & -0.049 & -0.038 & $-1.819^{* * * *}$ & -0.094 & -0.113 & -1.772 \\
\hline & $(0.765)$ & $(0.380)$ & (3.639) & $(0.891)$ & $(0.616)$ & (1.395) \\
\hline \multirow[t]{2}{*}{ S-Branch } & $-0.357^{* * *}$ & --- & --- & -0.181 & --- & --- \\
\hline & $(4.482)$ & & & $(0.874)$ & & \\
\hline \multirow[t]{2}{*}{ Box-Cox } & -0.061 & --- & $-0.762^{* * *}$ & -0.068 & --- & $-0.439^{* *}$ \\
\hline & $(0.679)$ & & (5.339) & $(0.593)$ & & $(2.284)$ \\
\hline \multirow[t]{2}{*}{ Other Form } & 0.090 & $-0.422^{* * *}$ & $-0.960^{* * * *}$ & 0.161 & $-0.478^{* *}$ & $-0.638^{* * * *}$ \\
\hline & $(0.948)$ & (2.906) & (7.010) & (1.285) & $(2.541)$ & $(5.400)$ \\
\hline
\end{tabular}




\section{Macrothink}

Business and Economic Research ISSN 2162-4860 2012, Vol. 2, No. 2

Table 1. Continued

\begin{tabular}{|c|c|c|c|c|c|c|}
\hline & & $\underline{\text { OLS }}$ & & & Random Effec & \\
\hline Variable & North America & Asia & Europe & North America & Asia & Europe \\
\hline Other Issues: & & & & & & \\
\hline Compensated & 0.067 & $0.219^{* * * *}$ & $0.221^{* * * *}$ & $0.105^{*}$ & $0.186^{* * *}$ & $0.223^{* * *}$ \\
\hline & (1.182) & $(4.497)$ & $(6.737)$ & (1.813) & (3.893) & (6.135) \\
\hline Substitute Meats & $-0.187^{* *}$ & 0.059 & $0.154^{* * * *}$ & $-0.185^{* *}$ & 0.078 & 0.096 \\
\hline & $(2.571)$ & $(0.981)$ & (3.011) & $(2.155)$ & $(0.668)$ & (1.449) \\
\hline Two-Step & $0.244^{* * * *}$ & $-0.158^{* * *}$ & -0.154 & $0.197^{*}$ & -0.112 & -0.254 \\
\hline & $(3.029)$ & $(2.397)$ & (1.006) & (1.696) & $(1.161)$ & $(0.849)$ \\
\hline Dynamic & -0.044 & $0.177^{* *}$ & -0.074 & -0.028 & -0.017 & $-0.142^{*}$ \\
\hline & $(0.808)$ & (2.316) & (1.163) & $(0.356)$ & $(0.118)$ & (1.819) \\
\hline Nature of Data: & & & & & & \\
\hline Time-Series & $-0.246^{* *}$ & $-0.226^{* *}$ & $0.817^{* *}$ & $-0.498^{* * * *}$ & -0.186 & 0.522 \\
\hline & $(2.442)$ & $(2.207)$ & (2.509) & (4.914) & $(0.755)$ & $(0.686)$ \\
\hline Cross-Sectional & 0.062 & $0.314^{* *}$ & $0.522^{* *}$ & -0.018 & $0.413^{* * * *}$ & 0.219 \\
\hline & $(0.317)$ & (2.499) & $(2.386)$ & $(0.096)$ & $(2.852)$ & $(0.922)$ \\
\hline Median Year & 0.003 & -0.002 & $-0.004^{*}$ & 0.006 & -0.002 & -0.003 \\
\hline & $(1.126)$ & $(0.730)$ & (1.739) & $(1.623)$ & $(0.446)$ & $(0.863)$ \\
\hline Data Aggregation: & & & & & & \\
\hline Multiple Countries & --- & --- & $-1.469^{* * *}$ & --- & --- & -1.011 \\
\hline & & & $(3.876)$ & & & (1.413) \\
\hline Country & $0.515^{* *}$ & $0.324^{*}$ & $-0.830^{* * *}$ & $0.708^{* * *}$ & 0.442 & -0.500 \\
\hline & (2.102) & (1.657) & $(2.511)$ & $(3.146)$ & (1.339) & $(0.742)$ \\
\hline Region of Country & $0.642^{*}$ & $0.558^{* * *}$ & $1.405^{* * *}$ & 0.646 & $0.694^{* * *}$ & $0.886^{*}$ \\
\hline & $(1.952)$ & (3.468) & $(4.011)$ & $(1.553)$ & (3.433) & (1.955) \\
\hline City & 0.118 & -0.063 & --- & 0.120 & -0.096 & --- \\
\hline & $(0.618)$ & $(0.722)$ & & $(0.551)$ & $(0.568)$ & \\
\hline Firm & $-0.708^{* * *}$ & --- & --- & -0.436 & --- & --- \\
\hline & $(2.661)$ & & & $(1.122)$ & & \\
\hline Estimation Method: & & & & & & \\
\hline 2 SLS & -0.103 & -0.044 & $-0.333^{*}$ & -0.383 & -0.011 & -0.266 \\
\hline & $(0.382)$ & $(0.278)$ & (1.876) & (1.388) & $(0.084)$ & (1.618) \\
\hline 3SLS & $-0.616^{* * * *}$ & -0.161 & -0.120 & -0.393 & -0.161 & -0.227 \\
\hline & $(3.489)$ & (1.448) & $(0.830)$ & (1.610) & (1.178) & (1.359) \\
\hline FIML & $-0.162^{* *}$ & $-0.419^{* * * *}$ & 0.106 & -0.103 & $-0.532^{* * *}$ & 0.079 \\
\hline & $(2.365)$ & $(2.686)$ & $(0.951)$ & $(0.872)$ & $(2.705)$ & $(0.308)$ \\
\hline MLE & 0.003 & -0.161 & 0.003 & -0.026 & -0.082 & -0.024 \\
\hline & $(0.063)$ & (1.229) & $(0.052)$ & $(0.212)$ & $(0.471)$ & $(0.232)$ \\
\hline
\end{tabular}


Table 1. Continued

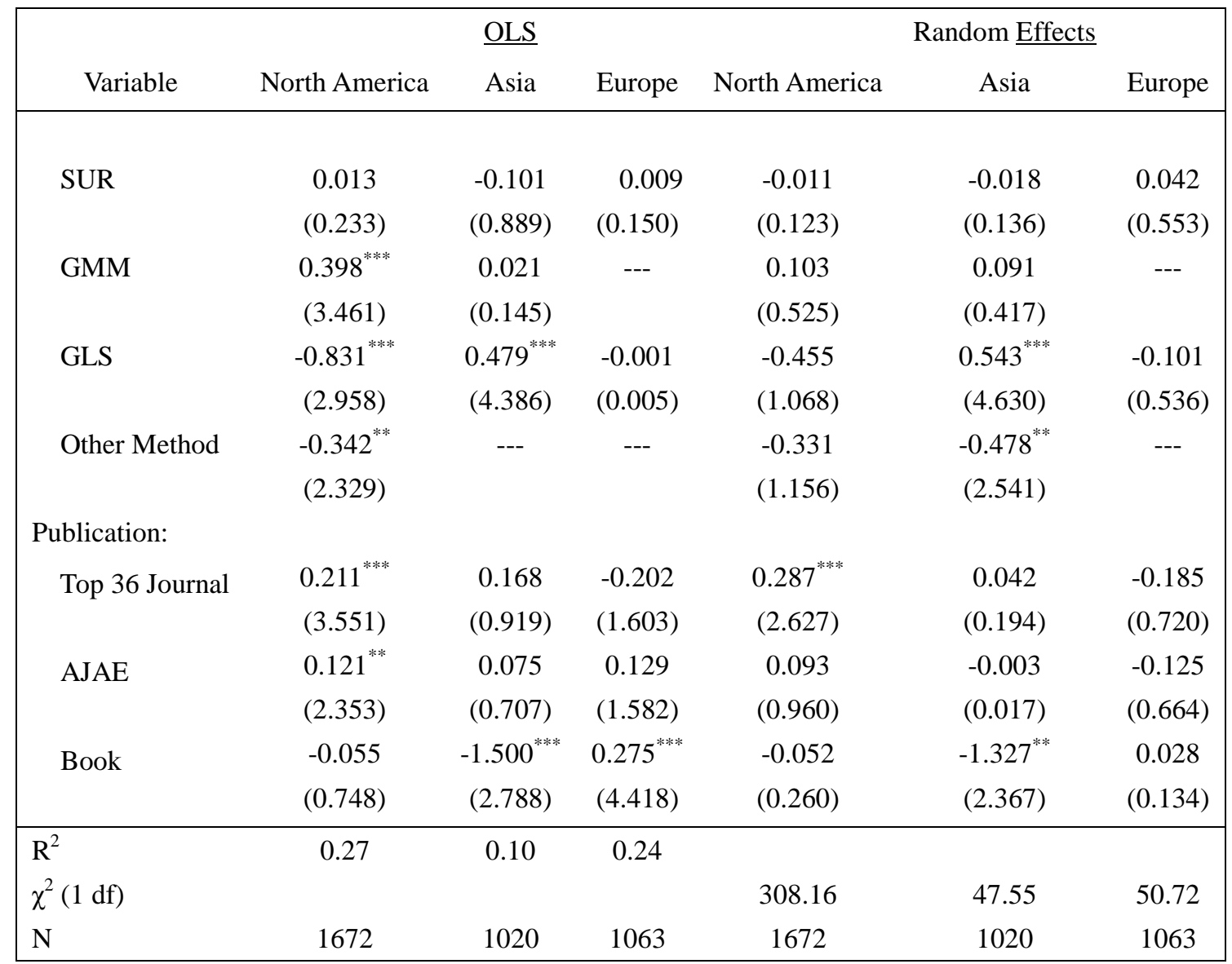

Note: t-statistics (in absolutevalue) provided in parentheses. Levels of significance: ${ }^{*}=10 \%,{ }^{* *}=5 \%$, and ${ }^{* * *}=1 \%$.

Concerning the different meats, relative to the baseline meat composite there are notable differences across the three regions. Consistent with Gallet (2010) there is a tendency in North America for the price elasticity to be more (less) elastic for beef, lamb, and fish (poultry), whereas the insignificant coefficient of pork implies the price elasticity of pork is statistically in the neighborhood of the meat composite. Yet for the other regions there are fewer significant differences in the price elasticity across meats. Although the signs of the coefficients are similar for North America and Asia, each of the meat product coefficients is insignificantly different from zero in the OLS results for Asia, while the random effects results for Asia indicate significantly more elastic price elasticities only for beef and lamb. For Europe, although beef and pork are more elastic (yet insignificantly so in the random effects results), the price elasticity of fish is significantly less elastic, which runs counter to North America.

Turning to specification issues, the functional form coefficients are most often negative and significant for Europe. Relative to the baseline linear specification of meat demand, other functional forms thus tend to generate more elastic estimates of the price elasticity in Europe. Yet for North America and Asia (especially in the random effects results) the larger share of coefficients being insignificant implies functional form plays a more modest role in 
determining the price elasticity. Region differences in the signs of many of the functional form coefficients, notably those that are significantly different zero (i.e., semi-log, AIDS-nonlinear, and CBS), as well as those associated with other specification issues (i.e., substitute meats and two-step treatments), also highlight that demand specification has different impacts on the price elasticity across regions. ${ }^{10}$

As for the remaining issues, the results are mixed. For instance, a greater share of the data-oriented coefficients in the OLS results for Europe are significantly different from zero, compared to North America and Asia. ${ }^{11}$ Yet when we examine the random effects results the lack of significance of most of these coefficients suggests data plays a less important role in determining the price elasticity. Although the OLS results for North America suggest the use of 3SLS, FIML, and GLS (GMM) contributes to more (less) elastic estimates of the price elasticity, significance of the estimation method coefficients drops off sharply for Asia and Europe, as well as for the random effects results. Finally, although more elastic estimates of the price elasticity in North America tend to be published in top 36 economics journals or the AJAE, for Asia and Europe the quality of the publication outlet matters less. ${ }^{12}$

\subsection{Predicted Price Elasticities}

The results in Table 1 show that study characteristics affect the price elasticity of meat differently from region to region. To get a better sense of these differences, we use the results in Table 1 to construct the predicted price elasticity for each meat product in North America, Asia, and Europe. Table 2 provides the absolute value of the predicted price elasticity for each meat product (along with its associated $95 \%$ prediction interval), based on the OLS and random effects results, holding each study characteristic dummy variable at its mean (with the exception of the dummy variables associated with every other meat product, which are set to zero).

Table 2 shows the predicted absolute price elasticities in North America and Asia for beef, lamb, and fish tend to exceed those of pork, poultry, and the meat composite. Yet many of the prediction intervals do overlap. Only in the case of North America do we find that beef, lamb, and fish demand are significantly more price elastic compared to poultry. As for Europe, while the absolute price elasticities of beef and lamb continue to remain high, we now find the price elasticity of fish to be lowest in absolute value (although only significantly different from the price elasticity of beef).

${ }^{10}$ Consistent across regions, though, the compensated price elasticity tends to be less elastic.

11 The OLS results reveal the price elasticity in Europe tends to be less (more) elastic when time-series or cross-sectional data is used to estimate meat demand that is aggregated to the region of a country, as compared to the use of panel data that is aggregated to the multiple country or country-level.

12 For Asia (Europe) more (less) elastic values tend to appear in book chapters. 
Table 2. Predicted absolute price elasticities by product and region

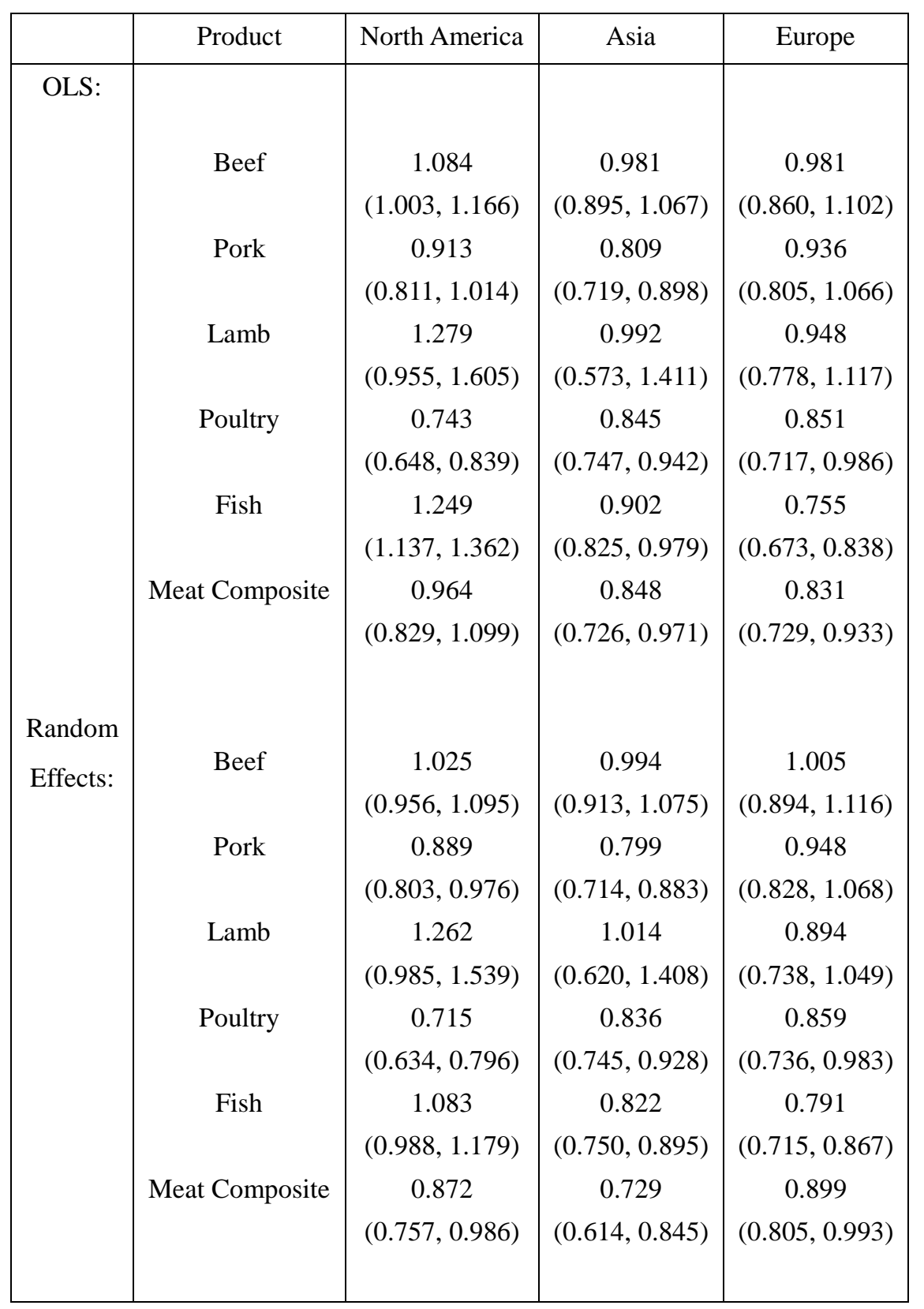

Note: Predicted absolute price elasticities for each product constructed by setting each study characteristic dummy variable equal to its mean, while the dummy variables for all other meat products are set to zero. Prediction intervals (at 95\%) are provided in parentheses below the point predictions.

\section{Concluding Comments}

In this study we quantitatively surveyed the literature to assess the impact of study characteristics on the price elasticity of meat in North America, Asia, and Europe. Among other issues, we found a greater tendency for the price elasticity to differ across meat products in North America, with the price elasticities of beef, lamb, and fish (poultry) falling in the elastic (inelastic) range. For Asia and Europe, there are not only fewer significant differences in the price elasticity across meat products, but in the case of Europe the price 
elasticity of fish noticeably falls in the inelastic range. Such results are consistent with differences in consumer preferences for meat across the three regions.

There are several benefits to having a more clear understanding of regional differences in the price elasticity of meat. For instance, in an effort to improve public health, consider a policymaker proposing to subsidize fish consumption by reducing the effective price of fish. Based on our results, such a policy would have a greater impact on fish consumption in North America than in Europe. Given that some study characteristics matter more in certain regions (e.g., functional form of demand in Europe), not only should greater attention be given to such issues when selecting a price elasticity from the literature, but more attention needs to be given as to why such differences exist.

\section{References}

Alston, J. M., \& Chalfant, J. A. (1991). Can we take the con out of meat demand studies? Western Journal of Agricultural Economics, 16, 36-48.

Asche, F., Bjørndal, T., \& Gordon, D. V. (2007). Studies in the demand structure for fish and seafood products. In A. Weintraub, C. Romero, T. Bjørndal, \& R. Epstein (Eds.), Handbook of Operations Research in Natural Resources. Berlin: Springer, 395-314.

Banks, J., Blundell, R., \& Lewbel, A. (1997). Quadratic Engel curves and consumer demand. $\begin{array}{llll}\text { Review of } \quad \text { Economics } & \text { 5nd }\end{array}$ http://dx.doi.org/10.1162/003465397557015

Bellavance, F., Dionne, G., \& Lebeau, M. (2009). The value of a statistical life: A meta-analysis with a mixed effects regression model. Journal of Health Economics, 28, 444-464. http://dx.doi.org/10.1016/j.jhealeco.2008.10.013

Bollino, C. A. (1990). GAIDS: A generalized version of the almost ideal demand system. Economics Letters, 34, 127-129. http://dx.doi.org/10.1016/0165-1765(90)90231-O

Dalhuisen, J. M., Florax, R. J. G. M., de Groot, H. L. F., \& Nijkamp, P. (2003). Price and income elasticities of residential water demand: a meta-analysis. Land Economics, 79, 292-308. http://dx.doi.org/10.2307/3146872

Deaton, A., \& Muellbauer, J. (1980). An almost ideal demand system. American Economic Review, 70, 312-326.

Espey, M. (1998). Gasoline demand revisited: an international meta-analysis of elasticities. Energy Economics, 20, 273-295. http://dx.doi.org/10.1016/S0140-9883(97)00013-3

Gallet, C. A. (2007). The demand for alcohol: a meta-analysis of elasticities. Australian Journal of Agricultural and Resource Economics, 51, 121-135. http://dx.doi.org/10.1111/j.1467-8489.2007.00365.x

Gallet, C. A. (2010). Meat meets meta: a quantitative review of the price elasticity of meat. American Journal of Agricultural Economics, 92, 258-272. http://dx.doi.org/10.1093/ajae/aap008 
Gallet, C. A., \& List, J. A. (2003). Cigarette demand: a meta-analysis of elasticities. Health Economics, 12, 821-835. http://dx.doi.org/10.1002/hec.765

Johnston, R. J., Ranson, M. H., Besedin, E. Y., \& Helm, E. C. (2006). What determines willingness to pay per fish? A meta-analysis of recreational fishing values. Marine Resource Economics, 21, 1-32.

Kuznets, G. M. (1953). Measurement of market demand with particular reference to consumer demand for food. Journal of Farm Economics, 35, 878-895. http://dx.doi.org/10.2307/1233281

Moschini, G., \& Moro, D. (1996). Structural change and demand analysis: a cursory review. European Review of Agricultural Economics, 23, 239-261. http://dx.doi.org/10.1093/erae/23.3.239

Raunikar, R., \& Huang, C. (1987). Food Demand Analysis: Problems, Issues, and Empirical Evidence. Ames, IA: Iowa State University Press.

Reeves, G. W., \& Hayman, A. H. (1975). Demand and supply forces in the world beef market. Quarterly Review of Agricultural Economics, 28, 121-151.

Rosenberger, R. S., \& Loomis, J. B. (2000). Panel stratification in meta-analysis of economic studies: an investigation of its effects in the recreation valuation literature. Journal of Agricultural and Applied Economics, 32, 459-470.

Scott, L.C., \& Mitias, P.M. (1996). Trends in rankings of economics departments in the U.S.: an $\quad$ Economic Inquiry, $34, \quad 300$. http://dx.doi.org/10.1111/j.1465-7295.1996.tb01383.x

Smallwood, D. M., Haidacher, R. C., \& Blaylock, J.R. (1989). A review of the research literature on meat demand. In R.Buse (Ed.), The Economics of Meat Demand. Madison, WI: Department of Agricultural Economics, University of Wisconsin, 93-124.

Tomek, W. G. (1977). Empirical analysis of the demand for food: a review. In R. Raunikar (Ed.), Food Demand and Consumption Behavior: Selected Research Topics. Athens, GA: The S-119 Southern Regional Research Committee and the Farm Foundation, 1-30.

White, H. (1980). A heteroskedasticity-consistent covariance matrix estimator and a direct test for heteroskedasticity. Econometrica, 48, 817-838. http://dx.doi.org/10.2307/1912934

\section{Copyright Disclaimer}

Copyright reserved by the author(s).

This article is an open-access article distributed under the terms and conditions of the Creative Commons Attribution license (http://creativecommons.org/licenses/by/3.0/). 